\title{
SCIDiC
}

\author{
International Journal of Dentistry and Oral Science (IJDOS) \\ ISSN: 2377-8075
}

\section{Prevalence Of Gingivitis During Circumpubertal Period Of 18-20 Years - A Retrospective Study}

Research Article

Oviya. V. $\mathrm{J}^{1}$, Jaiganesh Ramamurthy ${ }^{2 *}$, Deepa Gurunathan ${ }^{3}$

${ }^{1}$ Saveetha Dental college and Hospitals, Saveetha Institute of medical and Technical Sciences, Saveetha University, Chennai, India.

${ }^{2}$ Professor and Head, Department of Periodontics, Saveetha Dental College and hospitals, Saveetha Institute of Medical and Technical Sciences, Saveetha University, Chennai, India.

${ }^{3}$ Professor and Head, Department of Pedodontics and Preventive Dentistry, Saveetha Dental College and Hospitals, Saveetha Institute of Medical and Technical Sciences, Saveetha University, 162, Poonamallee High Road, Chennai - 600077, Tamil Nadu, India.

\section{Abstract}

Children and adolescents are subjected to various gingival infections. Chronic gingivitis is one of most common periodontal diseases affecting the children. Dental plaque is the major cause of gingivitis. However, it gets aggravated due to various secondary factors. Hormonal changes occurring during puberty cause enormous reaction in the inflamed gingiva. Dental practitioners have an important role in early recognition and diagnosis of gingival and periodontal diseases to improve the treatment outcome. Hence, the objective of this study is to evaluate the prevalence of gingivitis during circumpubertal periods in the age group of 18-20. A retrospective study was conducted. Data collection was done through reviewing records of 86000 patients visiting a hospital in Chennai from June(2019) to March(2020) A total of 37 patients who reported with gingivitis with their complete data were evaluated. Data such as age, gender, gingival index, plaque index were noted. Both frequency and Chi-square tests were done through IBM SPSS statistical analysis. Among the study population, $70.27 \%$ were males and $29.73 \%$ were females. About $24.32 \%$ of the patients were affected with severe gingivitis and $13.51 \%$ of the patients were reported with poor oral hygiene. Within the limits of this study, the prevalence of gingivitis during circumpubertal period is high in the age group of 18-20. Long term oral healthcare programme is highly recommended.

Keywords: Circumpubertal Period; Gingival Index; Gingivitis; Plaque Index; Prevalence.

\section{Introduction}

Oral health maintenance is essential to maintain overall health of the body. Periodontal diseases and dental caries are considered as multifactorial diseases which cause serious effects in the oral health of the patients [1]. They are one of the most prevalent oral diseases which can easily affect the individual whose oral hygiene is not maintained properly. If a periodontal diseases are not treated on time, it may cause destruction to tooth, soft tissues and bone [2].

Gingivitis is a reversible dental plaque induced inflammation of the gingiva without any bone loss and clinical attachment loss. It is one of the most frequently encountered cases in a dental practice affecting individuals of all ages [3]. Untreated gingivitis can pro- gress to periodontitis. But not all gingivitis will progress to periodontitis. Endotoxins produced by the pathogens of subgingival flora are the prerequisite for periodontal diseases [4]. Gingivitis is caused by multiple factors in which one or more factors together causes inflammation to the soft tissues of the periodontium [5]. These factors include bacteria, biofilm, genetic, socioeconomic, demographic, iatrogenic and behavioural factors [6]. However plaque induced gingivitis is the most common form of periodontal diseases [7].

Children and adolescents are affected by various forms of periodontal diseases including chronic gingivitis, localised or generalised aggressive periodontitis, etc [8]. Chronic gingivitis is the most common periodontal infection in children and adolescents. It can occur in various forms in children, which can be aggravated by many factors which includes plaque, steroid hormones, drugs

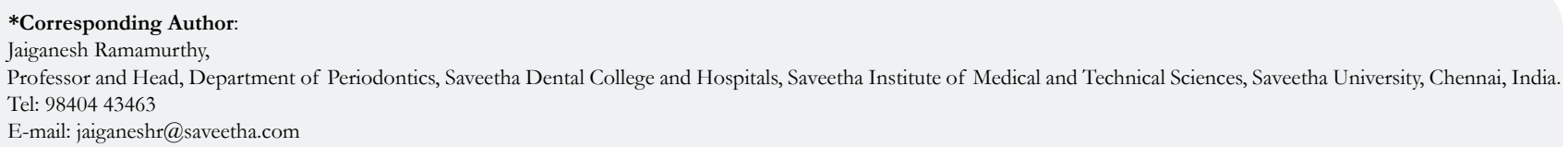

Copyright: Jaiganesh Ramamurthy ${ }^{\circ} 21$. This is an open-access article distributed under the terms of the Creative Commons Attribution License, which permits unrestricted use, distribution and reproduction in any medium, provided the original author and source are credited. 
etc, [3].

The prevalence and incidence of gingivitis varies with different countries and different studies due to the variation in the study population, age and research methodology. Several studies have shown that the prevalence of gingivitis increases markedly during puberty. During adolescence, there appears to be an increase in the prevalence of gingivitis varying from $50-90 \%[9,10]$. The clinical examination and several indices are used for determining the severity of the gingival inflammation. Gingival index and plaque index have been used widely to characterise the disease. Though its reliability is still unclear [1], the presence of these signs of inflammation is considered as the initial stage for more severe and irreversible forms of periodontal diseases [11].

Gingival inflammation can be prevented by maintaining good oral hygiene with proper dental plaque control. Since, gingival inflammation is considered to be a prerequisite for the development of periodontitis, impelling personal plaque control may be appraised as a primary prevention strategy to conflict the occurrence of periodontitis [12].

Prevention of dental plaque and early treatment of gingivitis reduced the risks of developing into more severe stages of periodontal diseases. It is necessary to collect detailed data regarding the gingivitis, to eliminate the factors which influence its incidence in the population. Previously our team has a rich experience in working on various research projects across multiple disciplines [13-27]. Hence, the aim and objective of the present retrospective study is to evaluate the prevalence of gingivitis during circumpubertal period in the age group of 18-20.

\section{Materials And Methods}

\section{Sampling}

This study was conducted in a university setting. The study samples were chosen from the patients visiting a hospital in Chennai from June(2019) to March(2020).

\section{Data collection}

The retrospective study was carried out among patients of age group 18-20. Data collection was done through reviewing the records of 86000 patients between June (2019) - March (2020). A total of 37 patients reported with gingivitis in the age group of 18-20 with complete data. Data such as patient's age, gender, gingival index, plaque index were noted.

\section{Inclusion criteria}

Only the patients aged 18-20 years visiting the hospital with complete data were included.

\section{Exclusion criteria}

Patients with severe systemic diseases, periodontitis and under special care were excluded.

Patients who are not recorded with plaque and gingival index with the presence of gingivitis were excluded.

Incomplete/censored data were excluded too.

\section{Approval}

Ethical clearance was obtained from the Institutional Scientific Review Board of the Saveetha University(SDC/SIHEC/2020/ DIASDATA/0619-0320).

\section{Data analysis}

The data collected was entered in the excel sheet and transferred to SPSS software. Data was analysed using SPSS software though frequency distribution and Chi-square tests.

\section{Results And Discussion}

In the present study, 37 patients presented with gingivitis in the age group of $18-20$. Among them $35.14 \%$ of the patients were 19 years old and $32.43 \%$ of the patients belonged to 18 and 20 years of age(Graph 1). Among them, the prevalence of gingivitis was more among males $(70.27 \%$ ) than females $(29.73 \%$ )(Graph 2). About $56.76 \%$ of the patients presented with fair oral hygiene, $29.73 \%$ of the patients presented with good oral hygiene and about $13.51 \%$ of the patients presented with poor oral hygiene. The mean score of the plaque index(PI) was 1.31.

About 45.95 of the patients had moderate gingivitis, $29.73 \%$ had mild gingivitis and about $24.32 \%$ of the patients had severe gingivitis. The mean score of the gingival index(GI) was 1.47.

There was a higher prevalence of moderate gingivitis in the study population, which is statistically significant (Chi-square; $\mathrm{p}<0.05)$ (Graph 3). The gingival index was comparatively higher among males than the females. Severe gingivitis was more prevalent among males (Graph 4).

Graph 1. Pie chart showing the distribution of study population with gingivitis based on age. There was a higher prevalence of gingivitis in the age of 19 years(35.14\%-violet).

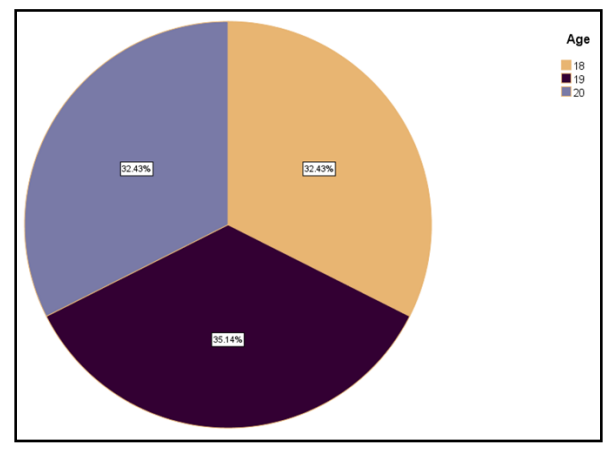


Graph 2. Pie chart showing the distribution of study population with gingivitis based on gender. There was a higher prevalence of gingivitis in males(70.27\%-pink) compared to females(29.73\%-blue).

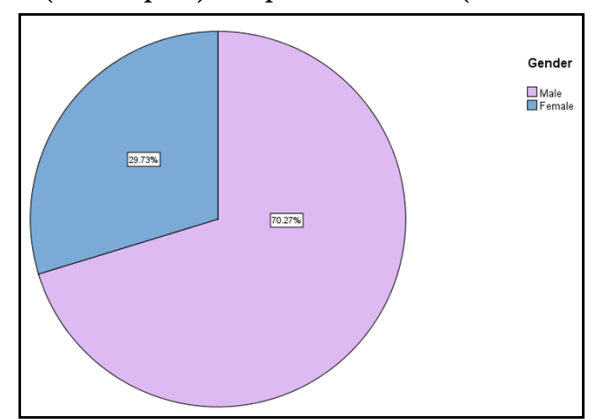

Graph 3. Bar chart showing the distribution of study population with gingivitis based on gingival index according to the age. $\mathrm{X}$-axis shows the age distribution and Y-axis shows the distribution of the study population based on the gingival index. There was a higher prevalence of moderate gingivitis(grey) in the age group of 18 years $(21.62 \%)$ and 20 years(18.92\%) and mild gingivitis(dark blue) in 19 years(18.92\%). This finding was statistically significant.(Chi square test $; 2=9.160, \mathrm{df}=4$, pValue $=0.057(<0.05))$.

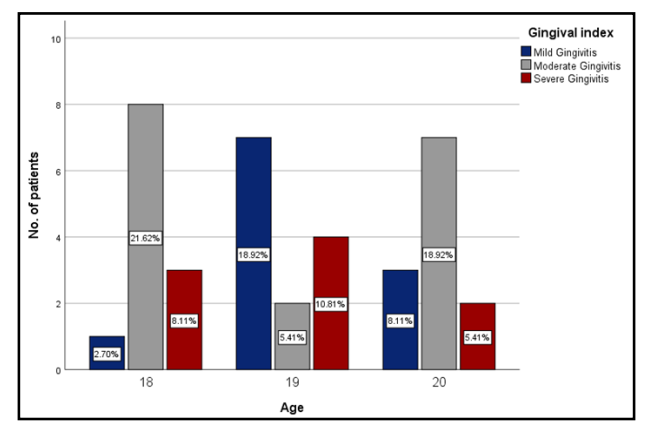

Graph 4. Bar chart showing the distribution of study population with gingivitis based on gingival index according to the gender. $\mathrm{X}$-axis shows the gender distribution and Y-axis shows the distribution of the study population based on the gingival index. There was a higher prevalence of moderate gingivitis(grey) in both males $(32.43 \%)$ and females(13.51\%) and however, this finding was not statistically significant.(Chi square test; $\chi 2=0.475$, $\mathrm{df}=2$, $\mathrm{pValue}=0.788(>0.05))$.

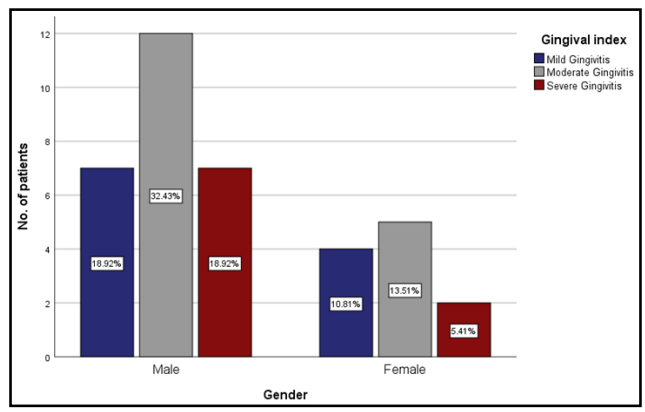

Graph 5. Bar chart showing the distribution of study population with gingivitis based on plaque index according to the age. $\mathrm{X}$-axis shows the age distribution and Y-axis shows the distribution of the study population based on the plaque index. There was a higher prevalence of fair oral hygiene(green) in the age group of 18-20 years, however which was not statistically significant. $($ Chi square test; $\chi 2=4.463, \mathrm{df}=4, \mathrm{pValue}=0.347(>0.05))$.

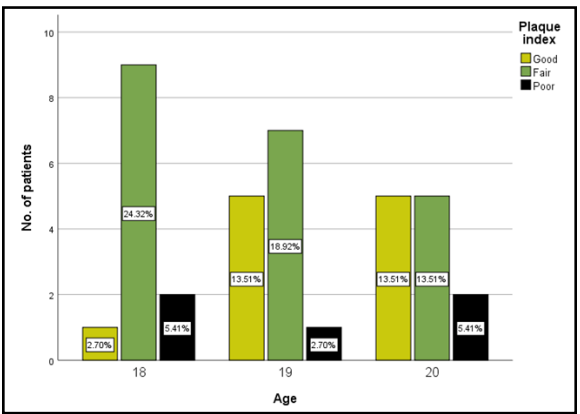

In the present study, oral hygiene status based on plaque index decreases as the age increases. There was a higher prevalence of fair oral hygiene in the study population (Graph 5). There was a statistically higher prevalence of poor oral hygiene among males than females (Graph 6). There was a statistically significant association between plaque index and gingival index. Moderate gingivitis were more prevalent with higher prevalence of fair oral hygiene.
Gingivitis is a reversible and non-destructive form of periodontitis usually presented with inflammation in marginal gingival which may progress to include attached gingiva but causing no attachment loss [28]. It can be acute or chronic in nature, occurring in all age groups. Diagnosis of various types of gingivitis mainly relied on the clinical findings and manifestations including redness, edema of the marginal gingiva, and bleeding upon probing [29]. If the disease persists, margin may become rolled with bulbous and enlarged interdental papilla and spontaneous bleeding with 
Graph 6. Bar chart showing the distribution of study population with gingivitis based on plaque index according to the gender. $\mathrm{X}$-axis shows the gender distribution and Y-axis shows the distribution of the study population based on the plaque index. There was a higher prevalence of poor oral hygiene(black) among males $(13.51 \%)$ compared to the females $(0 \%)$, which was however not statistically significant. $($ Chi square test; $\chi 2=2.851$, $\mathrm{df}=2$, $\mathrm{pValue}=0.240(>0.05))$.

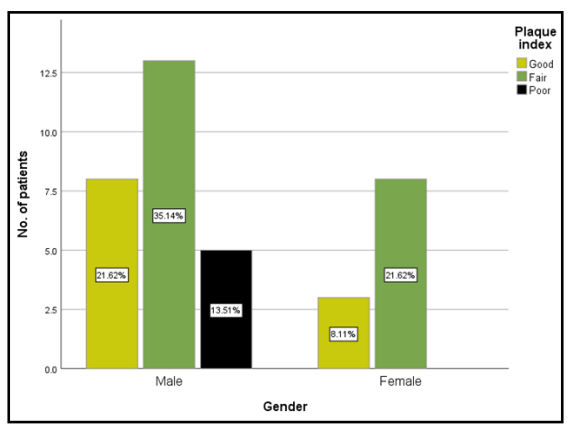

increased probing depth [30].

Gingivitis may exhibit various patterns of signs and symptoms of inflammation that are mainly localised to gingiva. However, systemic factors including endocrinopathies, hematological conditions, diet, drugs etc can modify the inflammatory response [31]. Gingivitis during puberty gets exacerbated due to the increase in the level of oestrogen and testosterone in the gingival tissues. The cytoplasm of the gingival cells contains specific high affinity, low capacity receptors for both oestrogen and testosterone. Thus, causing vasodilation and proliferation which results in causing increased vascularity leading to the increased susceptibility to inflammation in the presence of local factors $[32,33]$.

The incidence and severity of gingivitis in adolescents are influenced by a variety of factors such as plaque levels, dental caries, crowding of the teeth, mouth breathing and tooth eruption [34]. However, numerous studies reported an increase in the incidence of gingivitis in circumpubertal period due to the dramatic rise of steroid hormones in both genders irrespective of the presence of plaque $[10,35,36]$.

In the present study, we studied the prevalence of gingivitis of the patients of age 18-20 years. However, comparable epidemiological data on gingivitis are scarce in this age group. Hence, this study has to compare with those in similar age groups.

About 37 patients reported with gingivitis in the age group of 18-20 from June(2019) - March(2020) in this study. Bendoraitiene et al [37] studied periodontal status of $18 \mathrm{yrs}$ old patients and reported that only $22.9 \%$ of the study population had healthy periodontium. Mizutani et al [38] reported that $14.7 \%$ of his study subjects of age group 18-19 years had healthy periodontium. A study by Hessari et al [39] reported that only $8.0 \%$ of the subjects of age 18 years had healthy periodontium.

In the present study, the gingivitis was more prevalent among males than females. This is in accordance with other previous study in which females had lower plaque index and gingival index $[40,41]$. This may be due to the increased concern of females towards their oral hygiene for their healthy lifestyle.

In the present study plaque index and gingival index were used to evaluate the level of inflammation as it has been used widely in epidemiological studies. The mean plaque index and gingival index for the total subjects was 1.31 and 1.47 respectively, which resulted in patients of age 18-20 years having fair oral hygiene with moderate gingivitis. These findings are in accordance with Taani et al [41] who reported plaque and gingival index scores were 1.63 and 1.67 respectively in 13-14 years old school children. A study by El-Qaderi also reported similar scores in 14-16 years of school children [42].

In recent years, the prevalence and severity of dental caries have been reduced due to the use of increased fluoridated toothpastes and preventive programmes. However, periodontitis diseases remain widespread and increase with age [43]. Early diagnosis, treatment and prevention are of utmost important to prevent severe periodontal diseases at later ages. Dental plaque is the main risk factor for the development of periodontal diseases [44].

Prevention and treatment of early stage of periodontal diseases are relatively simple and effecTo remove the incidence of hormonal influenced gingivitis, all the local irritants should be removed and scrupulous plaque control measures should be carried out. Parents and patients should be educated regarding profound effects of hormones on periodontal tissues and the need of oral hygiene management [45].

Adequate daily removal of dental plaque prevents periodontal and diseases and dental caries. The most common and effective way to promote oral hygiene is tooth brushing. Hence brushing twice every day with proper brushing technique is recommended to be adopted as a habit. Fluoride in the toothpaste decreases the incidence of dental caries with frequent brushing. Most behavioural patterns were established in early childhood. It is important to establish effective dental programs for oral health and practices targeted at younger people [46].

Oral health education programmed regarding oral hygiene knowledge, practices, plaque control and gingival health should be conducted for school children and parents. Post intervention of oral health programmes showed significant improvement in oral hygiene practices among the study population $[47,48]$. Epidemiological studies of periodontal status and oral hygiene are important part of such preventive programs.Our institution is passionate about high quality evidence based research and has excelled in various fields [49-59].

\section{Limitations}

This study has few limitations. Since this is a retrospective study, already recorded parameters only analysed and patients with complete data only included and the study setting is also limited to 
certain geographical locations. Parameters such as oral hygiene practices, adverse habits and socioeconomic status were not included in this study. Hence, cohort study with the inclusion of these parameters among a large population is required for further evaluation.

\section{Conclusion}

Within the limits of this study, the prevalence of gingivitis in the age group 18-20 is high. Since the knowledge of dental diseases, methods of prevention and to maintain oral hygiene is very poor, oral health care programs should be conducted in this age group to prevent the incidence and progress of severe periodontal diseases.

\section{Author's Contribution}

Oviya. V. J was the primary investigator and had a role in all aspects of this study. Along with that, Jaiganesh Ramamurthy and Deepa Gurunathan contributed equally to the structure, concept of the study and revealing of the investigation and were associated with the obtaining of study information. All Authors had access to the final report, had contributed to the analysis and discussion of the article and to have final responsibility regarding the choice to submit and affirmed the submitted adaptation.

\section{Acknowledgement}

I sincerely express my gratitude and acknowledgement to Dr.Jaiganesh Ramamurthy and Dr. Deepa Gurunathan and Dean and the management for their support and also thank the Research and IT department of Saveetha dental college for their affable assistance in analyzing the data.

\section{References}

[1]. Chrysanthakopoulos NA. Reasons for extraction of permanent teeth in Greece: a five-year follow-up study. Int Dent J. 2011 Feb;61(1):19-24.Pubmed PMID: 21382029.

[2]. Oh TJ, Eber R, Wang HL. Periodontal diseases in the child and adolescent. J Clin Periodontol. 2002 May;29(5):400-10.

[3]. Lang NP, Schätzle MA, Löe H. Gingivitis as a risk factor in periodontal disease. Journal of clinical periodontology. 2009 Jul;36 Suppl 10:3-8.

[4]. Mootha A, Malaiappan S, Jayakumar ND, Varghese SS, Toby Thomas J. The Effect of Periodontitis on Expression of Interleukin-21: A Systematic Review. Int J Inflam. 2016;2016:3507503.Pubmed PMID: 26998377.

[5]. Ramesh A, Varghese SS, Doraiswamy JN, Malaiappan S. Herbs as an antioxidant arsenal for periodontal diseases. J Intercult Ethnopharmacol. 2016 Jan 27;5(1):92-6.Pubmed PMID: 27069730.

[6]. Kazemnejad A, Zayeri F, Rokn AR, Kharazifard MJ. Prevalence and risk indicators of periodontal disease among high-school students in Tehran. East Mediterr Health J. 2008 Jan-Feb;14(1):119-25.Pubmed PMID: 18557459.

[7]. Califano JV. Research, Science and Therapy Committee American Academy of Periodontology. Position paper: periodontal diseases of children and adoles-cents. J. Periodontol.. 2003;74:1696-704.

[8]. Armitage GC. Development of a classification system for periodontal diseases and conditions. Northwest. Dent.. 2000 Nov 1;79(6):31-5.

[9]. KETABI M, Tazhibi M, MOHEB RS. The prevalance and risk factors of gingivitis among the children referred to Isfahan Islamic Azad University (Khorasgan Branch) Dental School, in Iran.2006.

[10]. Sutcliffe P. A longitudinal study of gingivitis and puberty. J Periodontal Res. $1972 \mathrm{Feb} ; 7(1): 52-8$.

[11]. Kornman KS, Page RC, Tonetti MS. The host response to the microbial challenge in periodontitis: assembling the players. Periodontol 2000. 1997 Jun;14:33-53.Pubmed PMID: 9567965.

[12]. Albandar JM, Buischi YA, Oliveira LB, Axelsson P. Lack of effect of oral hygiene training on periodontal disease progression over 3 years in adolescents.
J Periodontol. 1995 Apr;66(4):255-60.Pubmed PMID: 7782978.

[13]. Hafeez N. Accessory foramen in the middle cranial fossa. Res J Pharm Technol. 2016 Nov 1;9(11):1880.

[14]. Krishnan RP, Ramani P, Sherlin HJ, Sukumaran G, Ramasubramanian A, Jayaraj G, et al. Surgical Specimen Handover from Operation Theater to Laboratory: A Survey. Ann Maxillofac Surg. 2018 Jul-Dec;8(2):234-238. Pubmed PMID: 30693238.

[15]. Somasundaram S, Ravi K, Rajapandian K, Gurunathan D. Fluoride Content of Bottled Drinking Water in Chennai, Tamilnadu. J Clin Diagn Res. 2015 Oct;9(10):ZC32-4.Pubmed PMID: 26557612.

[16]. Felicita AS. Orthodontic extrusion of Ellis Class VIII fracture of maxillary lateral incisor - The sling shot method. Saudi Dent J. 2018 Jul;30(3):265269.Pubmed PMID: 29942113.

[17]. Kumar S, Rahman RE. Knowledge, awareness, and practices regarding biomedical waste management among undergraduate dental students. Asian J Pharm Clin Res. 2017;10(8):341.

[18]. Gurunathan D, Shanmugaavel AK. Dental neglect among children in Chennai. J Indian Soc Pedod Prev Dent. 2016 Oct 1;34(4):364.

[19]. Sneha S. Knowledge and awareness regarding antibiotic prophylaxis for infective endocarditis among undergraduate dental students. Asian J Pharm Clin Res. 2016 Oct 1:154-9.

[20]. Dhinesh B, Lalvani JI, Parthasarathy M, Annamalai K. An assessment on performance, emission and combustion characteristics of single cylinder diesel engine powered by Cymbopogon flexuosus biofuel. Energy Convers. Manag. 2016 Jun 1;117:466-74.

[21]. Choudhari S, Thenmozhi MS. Occurrence and Importance of Posterior Condylar Foramen. LATERALITY. 2016 Aug 28;8:11-43.

[22]. Paramasivam A, Vijayashree Priyadharsini J, Raghunandhakumar S. N6adenosine methylation (m6A): a promising new molecular target in hypertension and cardiovascular diseases. Hypertens Res. 2020 Feb;43(2):153154.Pubmed PMID: 31578458.

[23]. Wu F, Zhu J, Li G, Wang J, Veeraraghavan VP, Krishna Mohan S, et al. Biologically synthesized green gold nanoparticles from Siberian ginseng induce growth-inhibitory effect on melanoma cells (B16). Artif Cells Nanomed Biotechnol. 2019 Dec;47(1):3297-3305.Pubmed PMID: 31379212.

[24]. Palati S, Ramani P, Shrelin HJ, Sukumaran G, Ramasubramanian A, Don $\mathrm{KR}$, et al. Knowledge, Attitude and practice survey on the perspective of oral lesions and dental health in geriatric patients residing in old age homes. Indian J Dent Res. 2020 Jan-Feb;31(1):22-25.Pubmed PMID: 32246676

[25]. Saravanan M, Arokiyaraj S, Lakshmi T, Pugazhendhi A. Synthesis of silver nanoparticles from Phenerochaete chrysosporium (MTCC-787) and their antibacterial activity against human pathogenic bacteria. Microb Pathog. 2018 Apr;117:68-72.Pubmed PMID: 29427709.

[26]. Govindaraju L, Gurunathan D. Effectiveness of Chewable Tooth Brush in Children-A Prospective Clinical Study. J Clin Diagn Res. 2017 Mar;11(3):ZC31-ZC34.Pubmed PMID: 28511505.

[27]. Vijayakumar Jain S, Muthusekhar MR, Baig MF, Senthilnathan P, Loganathan S, Abdul Wahab PU, et al. Evaluation of Three-Dimensional Changes in Pharyngeal Airway Following Isolated Lefort One Osteotomy for the Correction of Vertical Maxillary Excess: A Prospective Study. J Maxillofac Oral Surg. 2019 Mar;18(1):139-146.Pubmed PMID: 30728705.

[28]. Clerehugh V, Tugnait A. Diagnosis and management of periodontal diseases in children and adolescents. Periodontol 2000. 2001 Jun;26(1):146-68.

[29]. Pihlstrom BL, Michalowicz BS, Johnson NW. Periodontal diseases. lancet. 2005 Nov 19;366(9499):1809-20.

[30]. Mariotti A. Dental plaque-induced gingival diseases. Ann Periodontol. 1999 Dec;4(1):7-17.

[31]. Kinane DF. Periodontitis modified by systemic factors. Ann Periodontol. 1999 Dec;4(1):54-64.

[32]. Tiainen L, Asikainen S, Saxén L. Puberty-associated gingivitis. Community Dent Oral Epidemiol. 1992 Apr;20(2):87-9.Pubmed PMID: 1555394.

[33]. Pari A, Ilango P, Subbareddy V, Katamreddy V, Parthasarthy H. Gingival diseases in childhood-A review. J Clin Diagn Res. 2014 Oct;8(10):ZE01-4.

[34]. Stamm JW. Epidemiology of gingivitis. J Clin Periodontol. 1986 May;13(5):360-6.

[35]. Mariotti A. Sex steroid hormones and cell dynamics in the periodontium. Crit Rev Oral Biol Med. 1994 Jan;5(1):27-53.

[36]. Mombelli A, Gusberti FA, van Oosten MA, Lang NP. Gingival health and gingivitis development during puberty. A 4-year longitudinal study. J Clin Periodontol. 1989 Aug;16(7):451-6.Pubmed PMID: 2768539.

[37]. Bendoraitienė E, Zūbienė J, Vasiliauskienė I, Saldūnaitė K, Andruškevičienė $\mathrm{V}$, Basevičienė N, et al. Periodontal status in 18-year-old Lithuanian adolescents: An epidemiological study. Medicina (Kaunas). 2017;53(4):253-258. Pubmed PMID: 28668306.

[38]. Mizutani S, Ekuni D, Furuta M, Tomofuji T, Irie K, Azuma T, et al. Effects of self-efficacy on oral health behaviours and gingival health in university students aged 18- or 19-years-old. J Clin Periodontol. 2012 Sep;39(9):844- 
9.Pubmed PMID: 22780323.

[39]. Hessari H, Vehkalahti MM, Eghbal MJ, Samadzadeh H, Murtomaa HT. Oral health and treatment needs among 18-year-old Iranians. Med Princ Pract. 2008;17(4):302-7.Pubmed PMID: 18523398.

[40]. Furuta M, Ekuni D, Irie K, Azuma T, Tomofuji T, Ogura T, et al. Sex differences in gingivitis relate to interaction of oral health behaviors in young people. J Periodontol. 2011 Apr;82(4):558-65.Pubmed PMID: 20936916.

[41]. Taani DQ. Trends in oral hygiene, gingival status and dental caries experience in 13-14-year-old Jordanian school children between 1993 and 1999. Int Dent J. 2001 Dec;51(6):447-50.Pubmed PMID: 11789712

[42]. El-Qaderi SS, Quteish Ta'ani D. Dental plaque, caries prevalence and gingival conditions of 14-15-year-old schoolchildren in Jerash District, Jordan. Int J Dent Hyg. 2006 Aug;4(3):150-3.Pubmed PMID: 16958744.

[43]. Ericsson JS, Östberg AL, Wennström JL, Abrahamsson KH. Oral healthrelated perceptions, attitudes, and behavior in relation to oral hygiene conditions in an adolescent population. Eur J Oral Sci. 2012 Aug;120(4):335-41. Pubmed PMID: 22813224.

[44]. Bartold PM, Van Dyke TE. Periodontitis: a host-mediated disruption of microbial homeostasis. Unlearning learned concepts. Periodontol 2000. 2013 Jun;62(1):203-17.

[45]. Jafri Z, Bhardwaj A, Sawai M, Sultan N. Influence of female sex hormones on periodontium: A case series. J Nat Sci Biol Med. 2015 Aug;6(Suppl 1):S146-9.Pubmed PMID: 26604605

[46]. Murray JJ. Efficacy of preventive agents for dental caries. Caries Res. 1993;27(Suppl. 1):2-8.

[47]. D'Cruz AM, Aradhya S. Impact of oral health education on oral hygiene knowledge, practices, plaque control and gingival health of 13- to 15-yearold school children in Bangalore city. Int J Dent Hyg. 2013 May;11(2):12633.Pubmed PMID: 22747831.

[48]. Shenoy RP, Sequeira PS. Effectiveness of a school dental education program in improving oral health knowledge and oral hygiene practices and status of 12- to 13-year-old school children. Indian J Dent Res. 2010 AprJun;21(2):253-9.Pubmed PMID: 20657097.

[49]. Vijayashree Priyadharsini J. In silico validation of the non-antibiotic drugs acetaminophen and ibuprofen as antibacterial agents against red complex pathogens. J Periodontol. 2019 Dec;90(12):1441-1448.Pubmed PMID: 31257588 .
[50]. PC J, Marimuthu T, Devadoss P, Kumar SM. Prevalence and measurement of anterior loop of the mandibular canal using CBCT: A cross sectional study. Clin Implant Dent Relat Res. 2018 Apr 6;20(4):531-4.

[51]. Ramesh A, Varghese S, Jayakumar ND, Malaiappan S. Comparative estimation of sulfiredoxin levels between chronic periodontitis and healthy patients - A case-control study. J Periodontol. 2018 Oct;89(10):1241-1248.Pubmed PMID: 30044495.

[52]. Ramadurai N, Gurunathan D, Samuel AV, Subramanian E, Rodrigues SJ. Effectiveness of $2 \%$ Articaine as an anesthetic agent in children: randomized controlled trial. Clin Oral Investig. 2019 Sep;23(9):3543-50.

[53]. Sridharan G, Ramani P, Patankar S, Vijayaraghavan R. Evaluation of salivary metabolomics in oral leukoplakia and oral squamous cell carcinoma. J Oral Pathol Med. 2019 Apr;48(4):299-306.

[54]. Ezhilarasan D, Apoorva VS, Ashok Vardhan N. Syzygium cumini extract induced reactive oxygen species-mediated apoptosis in human oral squamous carcinoma cells. J Oral Pathol Med. 2019 Feb;48(2):115-121.Pubmed PMID: 30451321.

[55]. Mathew MG, Samuel SR, Soni AJ, Roopa KB. Evaluation of adhesion of Streptococcus mutans, plaque accumulation on zirconia and stainless steel crowns, and surrounding gingival inflammation in primary molars: randomized controlled trial. Clin Oral Investig. 2020 Sep;24(9):1-6.Pubmed PMID: 31955271

[56]. Samuel SR. Can 5-year-olds sensibly self-report the impact of developmental enamel defects on their quality of life? Int J Paediatr Dent. 2021 Mar;31(2):285-286.Pubmed PMID: 32416620.

[57]. R H, Ramani P, Ramanathan A, R JM, S G, Ramasubramanian A, et al. CYP2 C9 polymorphism among patients with oral squamous cell carcinoma and its role in altering the metabolism of benzo[a]pyrene. Oral Surg Oral Med Oral Pathol Oral Radiol. 2020 Sep;130(3):306-312.Pubmed PMID: 32773350.

[58]. Chandrasekar R, Chandrasekhar S, Sundari KKS, Ravi P. Development and validation of a formula for objective assessment of cervical vertebral bone age. Prog Orthod. 2020 Oct 12;21(1):38.Pubmed PMID: 33043408.

[59]. Vijayashree Priyadharsini J, Smiline Girija AS, Paramasivam A. In silico analysis of virulence genes in an emerging dental pathogen A. baumannii and related species. Arch Oral Biol. 2018 Oct;94:93-98.Pubmed PMID: 30015217. 